\title{
Health technology assessment in the Philippines
}

\author{
Madeleine De Rosas-Valera \\ Philippine Health Insurance Corporation
}

\begin{abstract}
Objectives: The aim of this study was to discuss the development of health technology assessment (HTA) in the Philippines.

Methods: A new national health insurance program began to be implemented in the Philippines in 1995 after passage of the Health Insurance Act.

Results: The program is known as the Philippine Health Insurance Corporation (PhilHealth). HTA was introduced to the Philippines in 1998. PhilHealth began to develop an HTA program subsequently.

Conclusions: As a developing country struggling to provide comprehensive health care to all citizens, PhilHealth sees HTA as an essential part of assuring that only effective and cost-effective care is provided for the public sector.
\end{abstract}

Keywords: Health technology assessment, Philippines, Health policy, Health planning, Health insurance

The Philippines government is an emerging democracy. Its healthcare system consists of both public and private providers, wherein the latter is dominant in terms of numbers.

Under the 1995 Health Insurance Act, a National Health Insurance Program began to be implemented, in which the intention is to cover the entire population needing access to health care, but especially the indigent population, to be phased in over time. The Philippine Health Insurance Corporation (PhilHealth), a government-owned and controlled corporation attached to the Department of Health, administers the national health insurance. In 2003, 55 percent of total health expenditures were out of pocket. The intention is to gradually replace much of this expenditure by tax revenues (1).

The Philippines has had a rather typical approach to health technology for a developing country: high drug expenditures, irrational prescribing, and an inadequate approach to controlling access, quality, and costs of health care.

The private system of care is essentially uncontrolled. In the public system, health technology assessment (HTA) is expected to play an increasingly important role.

\section{HISTORICAL BACKGROUND}

HTA in the Philippines can probably be traced to several key individuals, notably Drs. Tessa Tan Torres and Jose (Lito)
Acuin. Tan Torres was professor of epidemiology at the University of the Philippines and learned about HTA in some of her international contacts in the mid-1990s. Acuin is professor of Ear-Nose-Throat (ENT) at De La Salle University, and was selected for training in clinical epidemiology in the Rockefeller Foundation program (INCLEN), where he also became interested in HTA.

In 1998, Acuin, Agnette Peralta (Director of the Bureau of Health Devices and Technology of the Department of Health) and others decided to organize a course on HTA. They invited Dr. David Banta to come to Manila to participate in the course. The Philippine Health Insurance Corporation (PhilHealth) asked to make a statement as part of the course. During this statement, the spokesperson for PhilHealth stated that the organization intended to develop HTA as one of its most important tools. Subsequently, Acuin and Madeleine de Rosas-Valera (then Vice-President of the Quality Assurance Research and Policy Development Group of PhilHealth) met and decided to work together on the HTA program. Acuin has been acting as the chairman of the HTA committee mentioned below since that time.

The Health Technology Assessment (HTA) Committee of the PhilHealth was established in March 1999 (2) to develop reimbursement policies on medical claims based on the cost-effectiveness of tests and treatments.

In the same year, by virtue of Memorandum Circular No. 9, PhilHealth took part in the implementation of the Philippine Generics Law, Rational Drug Use and Principles 
of Good Prescribing. Under this circular, reimbursements of claims for drugs not listed in the latest edition of the Philippine National Drug Formulary (PNDF) and not written with their generic names will be disallowed or denied payment. However, the HTA Committee was authorized to arbitrate on appeals and questions on the effectiveness of drugs that were introduced in the Philippine market but were not listed in the PNDF. With this authority, the HTA Committee comes up with a positive list of drugs that are not listed in the PNDF but may still be reimbursed by PhilHealth (2).

\section{FUNCTIONS OF THE HTA COMMITTEE}

There are three major programs of the HTA Committee:

\section{Conduct of Drug Assessments to Determine Which Drugs Should and Should not be Reimbursed by PhilHealth}

Drugs assessed to be effective, safe, and cost-effective are temporarily included in the PhilHealth positive list. The PhilHealth positive list consists of drugs that PhilHealth reimburses but are not yet included in the current edition of the Philippine National Drug Formulary (PNDF). The temporary nature of this list is underscored by its annual expiry date. Upon inclusion of the Positive List Drugs in the National Formulary Committee deliberation and its incorporation in the PNDF, the temporary list will cease to exist.

As the PNDF was revised in 2005, drugs in the Positive list have expired; and since then, PhilHealth has not yet conducted technology assessment of drugs for the purpose of inclusion to the Positive List.

Apart from drugs, the HTA Committee also evaluates the safety and effectiveness of medical devices and medical and surgical procedures.

\section{Appraisal and Dissemination of Clinical Practice Guidelines}

The clinical practice guidelines (CPGs) are chosen based on the most common reimbursable claims in PhilHealth. Specific recommendations on disease assessment, laboratory tests, drug treatments, and admission policies are extracted from the screened CPGs and assessed for applicability to local settings.

\section{Evaluation of the Effectiveness and Safety of Medical and Surgical Procedures}

One of the goals of the Committee is to support provider's efforts in adhering to the law that accredited providers are required to use only effective and appropriate medical and surgical interventions.

To date, the HTA Committee has led in the evaluation of outpatient cataract surgery and antenatal and postnatal care for low-risk pregnancy. The results of these evaluations became inputs into the development of the benefit packages for these two health services. Works resulting from these three programs are regularly featured in issues of The HTA Forum.

\section{Composition}

At present, The HTA Committee consists of the following members: (i) Expert Panel on clinical epidemiology, family medicine, internal medicine, health economics, medical devices, pharmacology and toxicology, evidence-based medicine, surgical procedures, quality assurance improvement, biostatistics and health management, planning, and policy; and (ii) Department representatives from PhilHealth's Quality Assurance Group, Benefits Development and Research Department, and Accreditation Department, (iii) HTA Committee Secretariat.

\section{HTA's Official Publication: The HTA Forum}

The HTA Forum is the official publication of the HTA containing the recommendations and evidence reports of the drugs that were reviewed, prepared, and translated into policies by the Health Technology Assessment Committee and the Quality Assurance Group as part of the Corporation's information and education campaign.

It is a part of PhilHealth's commitment to provide information to doctors on why certain drugs are reimbursed and others are not. The drug assessments that the HTA Committee has conducted regularly appear in The HTA Forum to advise clinicians on the drug reimbursement policies of the Corporation. These assessments follow a highly structured process that allow for explicit and systematic evaluation of the best available evidence from the scientific literature. This process is discussed in Appendix A.

The first issue of The HTA Forum, which was disseminated in 2003 to PhilHealth accredited healthcare providers, generated enthusiastic responses from the medical and pharmaceutical communities. It also sent a clear and unmistakable signal that PhilHealth is for quality of health care.

The HTA Forum also features work resulting from other programs of HTA including the appraisal and dissemination of clinical practice guidelines developed by local medical societies used for reviewing reimbursement claims; and the evaluation of the effectiveness and safety of medical and surgical procedures.

\section{DISCUSSION}

HTA in PhilHealth deals with more than drugs on the Positive List. It is also focused on clinical practice guidelines and healthcare financing programs such as technologies that influence drug policies, payment decisions, and access to basic health care.

PhilHealth is fully committed to HTA as a tool for guiding the acceptance and use of health technology in its services. As population coverage by the National Health 
Insurance Program expands, HTA is also expected to grow in scope, investment, and depth. As a developing country struggling to provide comprehensive health care to all citizens, PhilHealth sees HTA is an essential part of ensuring that only effective and cost-effective care is provided in the public sector.

\section{CONTACT INFORMATION}

Madeleine De Rosas-Valera, MD, MScIH (Heidelberg) (madz_valera@yahoo.com), Senior Vice President for
Health Finance Policy and Services Sector, Philippine Health Insurance Corporation, CityState Center, 709 Shaw Boulevard, Brgy. Oranbo, 1600 Pasig City, Philippines

\section{REFERENCES}

1. ECORYS. Philippines - health care and reimbursement systems. Rotterdam, The Netherlands: ECORYS; 2008.

2. Valera M. HTA in the Philippines: Past, present, and future. In: Proceedings of the 4th HTAi Meeting, Barcelona, Spain; 2007. 